\title{
Transfer of Information from Personal Health Records: A Survey of Veterans Using My HealtheVet
}

Carolyn L. Turvey, Ph.D., ${ }^{1-3}$ Donna M. Zulman, M.D., M.S., ${ }^{4,5, *}$ Kim M. Nazi, FACHE, M.A., ${ }^{6}$ Bonnie J. Wakefield, Ph.D., R.N., FAAN, ${ }^{1,7}$ Susan S. Woods, M.D., M.P.H., ${ }^{8}$ Timothy P. Hogan, Ph.D., ${ }^{9,10}$ Frances M. Weaver, Ph.D., ${ }^{11}$ and Keith Mclnnes, Sc.D., M.S. ${ }^{12,13}$

${ }^{1}$ Center for Comprehensive Access \& Delivery Research and Evaluation (CADRE), lowa City VA Health Care System, lowa City, lowa.

${ }^{2}$ VA Office of Rural Health, Veterans Rural Health Resource Center-Central Region, Iowa City VA Health Care System, Iowa City, lowa.

${ }^{3}$ Department of Psychiatry, University of lowa, lowa City, lowa. ${ }^{4}$ Robert Wood Johnson Foundation Clinical Scholars Program, University of Michigan, Ann Arbor, Michigan.

${ }^{5}$ VA Ann Arbor Health Care System, Ann Arbor, Michigan.

${ }^{6}$ Veterans and Consumers Health Informatics Office, U.S. Department of Veterans Affairs, Washington, D.C.

${ }^{7}$ University of Missouri Sinclair School of Nursing, Columbia, Missouri.

${ }^{8}$ Portland VA Medical Center, Portland, Oregon.

${ }^{9}$ Center for Management of Complex Chronic Care, Spinal Cord Injury Quality Enhancement Research Initiative, and eHealth Quality Enhancement Research Initiative, Edward Hines Jr. VA Hospital, Hines, Illinois.

${ }^{10}$ Program in Health Services Research, Stritch School of Medicine, Loyola University Chicago, Maywood, Illinois.

${ }^{11}$ Department of Medicine, Stritch School of Medicine, Loyola University, Chicago, Illinois.

${ }^{12}$ Center for Health Quality Outcomes and Economic Research, ENRM Veterans Hospital, Bedford, Massachusetts.

${ }^{13}$ Department of Health Policy and Management, Boston University School of Public Health, Boston, Massachusetts. *Present address: Division of General Medical Disciplines, Stanford University, Stanford, California; Center for Health Care Evaluation, VA Palo Alto Health Care System, Menlo Park, California.

\footnotetext{
Abstract

Objective: Personal health records provide patients with ownership of their health information and allow them to share information with multiple healthcare providers. However, the usefulness of these records relies on patients understanding and using their records appropriately. My HealtheVet is a Web-based patient portal containing a personal health record administered by the Veterans Health Administration. The goal of this study was to explore veterans' interest
}

and use of My HealtheVet to transfer and share information as well as to identify opportunities to increase veteran use of the My HealtheVet functions. Materials and Methods: Two waves of data were collected in 2010 through an American Customer Satisfaction Index Webbased survey. A random sample of veterans using My HealtheVet was invited to participate in the survey conducted on the My HealtheVet portal through a Web-based pop-up browser window. Results: Wave One results $(\mathrm{n}=25,898)$ found that $41 \%$ ofveterans reported printing information, 21\% reported saving information electronically, and only 4\% ever sent information from My HealtheVet to another person. In Wave Two $(\mathrm{n}=18,471), 30 \%$ reported self-entering medication information, with $18 \%$ sharing this information with their Veterans Affairs (VA) provider and 9.6\% sharing with their non-VA provider. Conclusion: Although veterans are transferring important medical information from their personal health records, increased education and awareness are needed to increase use. Personal health records have the potential to improve continuity of care. However, more research is needed on both the barriers to adoption as well as the actual impact on patient health outcomes and well-being.

Key Words: e-health, medical records, telehealth

\section{Introduction}

$\mathrm{E}$ nhancing continuity of care is one of the most promising features of electronic personal health records (PHRs). PHRs can facilitate communication between patients and their providers from different healthcare systems and between patients and their informal caregivers. ${ }^{1,2}$ Giving patients' ownership of portions of their medical record allows them to share medical information while avoiding the time-consuming and cumbersome releaseof-information process. In addition, the Center for Information Technology Leadership estimates that electronic PHRs can save as much as 11 billion dollars annually for payer-administered systems. ${ }^{3}$ By improving care coordination, PHRs have the potential to reduce redundant care, medication errors, healthcare utilization, and cost. ${ }^{1-5}$

In this article, "transfer of information" refers to either saving or printing or sending it from one's PHR to another place. A PHR user might store this information elsewhere for personal use only or may transfer the information to another person such as a family caregiver or a healthcare provider. Transferring information is an essential step in the use of PHRs to improve communication between the patient and one or more healthcare providers. Therefore, it is important to understand if and how users perform this task.

In 2003, the Veterans Health Administration (VHA) of the U.S. Department of Veterans Affairs (VA) introduced My HealtheVet, a 


\section{TURVEY ET AL.}

Web-based patient portal containing a PHR. My HealtheVet provides information about health conditions, VA benefits, and location of VA services. For veterans receiving care at the VA, My HealtheVet is connected to their VA electronic medical record and allows several functions, such as online prescription refills or self entry in food or activity journals. At the time of this survey, approximately $20 \%$ of veterans receiving VA medical services were registered with My HealtheVet. In order to see actual medication names, veterans were required to be "In-Person Authenticated." In-person authentication occurs when a veteran presents in person to an authorized facility, such as a VA medical center, and has his or her identity verified. For this study, registered users who were not in-person authenticated could only see their prescription numbers, not the names of the medications, although this has since changed. Patients can access, save, and print their complete medication list and recent medication history. Patients who are in-person authenticated could see all their medication names on their complete medication list, whereas those who are registered could see only the medication numbers. As of January 2011, 30\% of veterans registered on My HealtheVet were inperson authenticated. The most common use of My HealtheVet is to refill prescriptions and access the full medication list. ${ }^{6}$

Many veterans, especially those living in rural areas or other locations far from VA facilities, receive care from both VA and non-VA providers, with Medicare being the primary insurer for non-VAdelivered care. Co-managed care is greater in rural areas ${ }^{7}$ and has been associated with negative outcomes. ${ }^{8}$ Although the VA has a nationwide electronic medical record, outside care providers do not have access to the VA medical record and must rely on transfer of records or patient report to obtain information about a patient's VA care. My HealtheVet offers an opportunity to improve care coordination by allowing veterans to quickly and conveniently share their health information with non-VA providers. ${ }^{9}$ The value of PHRs is highly dependent on the number of patients registered and the appropriate use of the PHR functions. ${ }^{3}$ This study presents data from two waves of quality assurance surveys within the VA designed to explore veterans' interest in and current use of My HealtheVet to transfer and share information.

\section{Materials and Methods}

The American Customer Satisfaction Index (ACSI) survey is a Web-based survey tool for assessing consumer satisfaction and preferences. It is produced by a partnership of the University of Michigan Business School, the American Society for Quality, and the CFI Group. Deployment of the ACSI across multiple federal Web sites of the National Institutes of Health from September 2004 to 2006 demonstrated the usefulness of ACSI as a standardized Web evaluation tool for government Web sites with public audiences. ${ }^{10}$

The ACSI survey is available on the My HealtheVet portal through a Web-based pop-up browser window. Using a sampling percentage of $4 \%$, a random sample of veterans using My HealtheVet who had viewed at least four pages within the site was invited to participate in the survey. This survey was conducted with all veterans using My HealtheVet and is therefore a nationwide sample of veteran My
HealtheVet users. A review of the full methods for this survey was published recently. ${ }^{6,11}$ The data presented herein were collected in a later administration of the survey, and thus this was the only survey including specific questions about what veterans do with the information in their PHR.

My HealtheVet is comparable to other PHRs in that it allows veterans to see their medication history, to enter health-related and contact information, and to search for information on health-related topics. Since the data for this study were collected, newer functions have been released such as secure messaging, appointment viewing, and chemistry/hematology results.

Data presented result from two surveys conducted in 2010: The first collected between February 26 and July 7 and the second collected between July 7 and October 4. In the first wave (Wave One), four custom questions were asked to specifically address the transfer of information from My HealtheVet to other places or persons. As My HealtheVet also includes information about benefits, nonmedical information may also be transferred.

Respondents were asked if they had ever printed, saved, or transferred information obtained in My HealtheVet, and if so, what type of information. Using branching logic, a positive response to some of the questions was followed by more in-depth questions. In the second survey (Wave Two), three questions addressed sharing medication information from My HealtheVet with both VA and nonVA providers. My HealtheVet allows veterans to enter non-VA medications, which are then combined with the VA medication list to make "My Complete Medication List." In the Wave Two assessment, veterans were also asked which types of medication they enter in their medication list. The sample size for specific variables varied slightly because of random nonresponse from veteran respondents.

\section{Results}

\section{WAVE ONE-TRANSFER OF INFORMATION}

The Wave One sample included 25,898 veteran respondents (45.6\% response rate). The largest group (47\%) was between 60 and 69 years of age (Table 1). Most rated their health as "Good" or "Very good," and 70\% had gone through the in-person authentication process, thereby gaining access to their full VA medication list. Most visited the My HealtheVet website once a month.

In response to whether respondents have ever printed, saved, or transferred information, 40\% $(n=10,488)$ reported that they had printed out information from My HealtheVet. A smaller portion, 21\% $(n=5,555)$, reported saving information from My HealtheVet electronically to their computer, and only $4 \%(n=1,013)$ reported ever sending information from My HealtheVet to another person. Table 2 shows the type of information respondents transferred and how.

Participants were then asked a hypothetical question (i.e., would they save information from their PHR to some place outside of My HealtheVet if they could). A considerable portion, 36\% $(n=9,235)$ responded "No," 30\% $(n=7,856)$ were not sure, $28 \%(n=7,175)$ responded "Yes," and 6\% $(n=1,632)$ reported this would not be useful. Of those responding "Yes" or "Not sure," Table 3 presents results of respondents' endorsement of where they would save their 
Table 1. Sample Characteristics of Wave One and Wave Two American Customer Satisfaction Index Respondents $N(\%)$

WAVE ONE SAMPLE WAVE TWO SAMPLE $(N=25,834)$ $(N=18,471)$

\begin{tabular}{l|c|c}
\multicolumn{1}{l|}{ Age (years) } & $715(3)$ & $469(3)$ \\
\hline $18-39$ & $1,937(7)$ & $1,396(8)$ \\
\hline $40-49$ & $5,350(21)$ & $3,753(20)$ \\
\hline $50-59$ & $12,263(47)$ & $8,969(48)$ \\
\hline $60-69$ & $5,569(22)$ & $3,890(21)$ \\
\hline $70+$ & $22,746(91)$ & $16,439(92)$ \\
\hline \% Male & \multicolumn{3}{|c}{} \\
\hline Self-rated health & $1,256(5)$ & $833(4)$ \\
\hline Excellent & $4,839(18)$ & $3,530(19)$ \\
\hline Very good & $9,919(38)$ & $7,011(38)$ \\
\hline Good & $7,671(29)$ & $5,511(29)$ \\
\hline Fair & $2,515(10)$ & $1,881(10)$ \\
\hline Poor &
\end{tabular}

Has the veteran been in-person authenticated?

\begin{tabular}{l|c|c}
\hline Yes & $18,466(71)$ & $13,103(70)$ \\
\hline No & $5,067(19)$ & $3,681(20)$ \\
\hline Not sure & $2,463(9)$ & $1,772(9)$ \\
\hline Not applicable & $204(1)$ & $210(1)$ \\
\hline
\end{tabular}

How frequently do you visit the My HealtheVet Web site?

\begin{tabular}{l|c|c}
\hline Daily & $1,390(5)$ & $1,000(5)$ \\
\hline Weekly & $6,366(24)$ & $4,603(25)$ \\
\hline Monthly & $13,017(50)$ & $8,852(47)$ \\
\hline About every 6 months & $1,481(6)$ & $1,122(6)$ \\
\hline $\begin{array}{l}\text { Less than every } \\
6 \text { months }\end{array}$ & $792(3)$ & $615(3)$ \\
\hline First-time visitor & $3,154(12)$ & $2,574(14)$ \\
\hline
\end{tabular}

information. Most would save the information to another place such as their own computer, although 37\% endorsed sharing the information with another person, be it a family member, friend, or nonVA physician. Twenty-two percent of this subgroup endorsed they would save the information to another PHR.

\section{WAVE TWO-SHARING OF MY COMPLETE MEDICATIONS LIST}

The Wave Two sample included 18,471 participants (40.8\% response rate). Table 1 demonstrates that the sample characteristics were comparable to those of Wave One, with the majority being 60-
69 years old, rating their health as "Very good" or "Good," and using the My HealtheVet Web site about once a month.

When asked if they use the self-entered function for tracking medications, 30\% $(n=5,490)$ indicated that they self-entered data about medications and supplements, 52\% $(n=9,552)$ did not use this function, and 19\% $(n=3,429)$ were not sure (Table 4). Veterans reported that information entered into "My Complete Medications List" was about over-the-counter medications (28\%), herbals and other supplements (23\%), VA prescriptions other than home VA facility (17\%), prescriptions from non-VA health providers (16\%), or prescription not filled at VA pharmacies (16\%). Of those using the selfentry function for tracking medications $(n=5,490), 60 \%$ shared their complete medication list with their VA providers, whereas $32 \%$ shared their complete medication list with non-VA providers.

\section{Discussion}

The proportion of My HealtheVet users reporting they had printed out information was $40 \%$, with $21 \%$ reporting saving information to their computer and 4\% reporting sending information to another person. The Wave Two data indicated that $18 \%$ were sharing their complete medication list with VA providers and that 9.6\% were sharing this information with non-VA providers. This shows that veterans are using My HealtheVet to improve the coordination of their care.

Most of the prior discourse of information transfer in PHRs focuses on data included in the medical record. This study reveals that many veterans are using My HealtheVet for functions other than medical record data (i.e., clarification and communication about benefits). In tandem with improving access and dissemination of medical record information, PHR vendors could expand user-friendly Web-based programs to educate patients and care providers about benefits. For example, in the case of the VHA, Web-based information about the VHA formulary or criteria for reimbursement of non-VA providers by VHA would enhance decision-making about medication choice or referral practice by veterans and non-VA providers.

The demographic data on users are comparable to those of the veteran population as a whole and suggest that older and less healthy veterans are making use of this technology. Although many are concerned about PHR adoption in the elderly, the majority of the respondents in this survey were 60 years of age or older. The most common frequency of use was monthly, which may indicate that veterans log on only when refilling prescriptions, the most common use for My HealtheVet. ${ }^{6}$ A considerable portion of respondents-40\% combined in both waves-rated themselves as having fair or poor health. Old age and poor health may be barriers to adoption, but the value of PHRs appears to motivate many to overcome these barriers. Consistent with prior reports on user satisfaction with My HealtheVet, ${ }^{6,11}$ a relatively small portion of veterans endorse transferring information from the PHR about food or activity journals. Similarly, the food and activity journals are underutilized compared with the medication management function of My HealtheVet. ${ }^{6}$

Although PHRs have enormous potential in documenting and providing structure for self-care in complex chronic illnesses, it 


\section{TURVEY ET AL.}

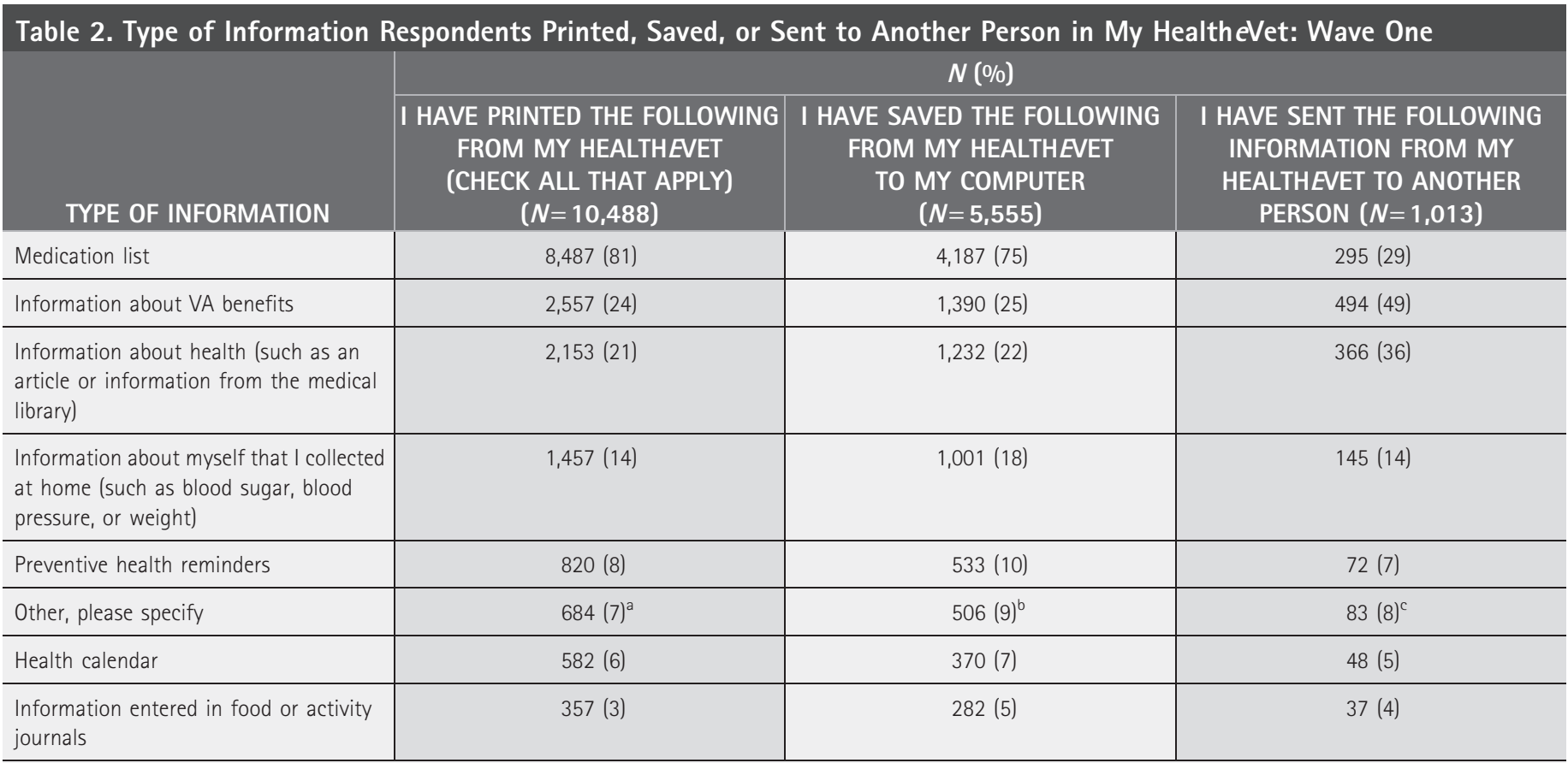

${ }^{a}$ Common responses: In-person authentication, emergency contact and info card, physician contact information card, and prescription review.

${ }^{b}$ Common responses: Download of Veterans Affairs (VA) form, one's password, emergency contacts, worksheets, the Web site address, insurance coverage, and immunization data.

'Common responses: Send information on how to use the site or diabetes information to others.

appears this potential is far from realized in this sample. More research is needed to determine whether the relatively low use of this function stems from lack of interest or from lack of awareness. Many veterans are voluntarily enrolled in home monitoring, which involves comparable reporting of self-care behaviors indicating some

Table 3. Respondents' Endorsement of Where They Would Save Their Health Information Outside of My HealtheVet If They Could: Wave One $(N=15,035)$

\begin{tabular}{|c|c|}
\hline & $N(\%)$ \\
\hline $\begin{array}{l}\text { Save the information to another place (for example, by } \\
\text { copying to a file on my computer) }\end{array}$ & $9,308(62)$ \\
\hline Share the information with a family member or friend & $5,627(37)$ \\
\hline Give the electronic information to my non-VA provider & $5,499(37)$ \\
\hline $\begin{array}{l}\text { Use the information with another program (for example, to } \\
\text { check for drug interactions) }\end{array}$ & $3,547(24)$ \\
\hline Put the information into another personal health record & $3,244(22)$ \\
\hline $\begin{array}{l}\text { Put the information in another Web site (for example, to } \\
\text { receive customized care recommendations or to use other } \\
\text { kinds of tools) }\end{array}$ & $956(6)$ \\
\hline $\begin{array}{l}\text { Other, please specify (common responses: "Back up," "print } \\
\text { paper copy to store," "flash drive," and "iPhone") }\end{array}$ & $586(4)$ \\
\hline
\end{tabular}

value of this function. Therefore, the delay of adoption of My HealtheVet for this purpose may well be due to lack of awareness.

Further exploratory work is needed to understand what veterans meant when they indicated "not sure" in response to the survey questions about transferring and sharing information. Although respondents may not have understood the question, it may also indicate a lack of understanding about the possibility of downloading information and why this could be useful. The high endorsement of "Not sure" suggests confusion about this function, which may be remedied with more education about potential uses of PHRs.

Although this study represents a large number of veteran users, some limitations of the study should be considered. ACSI survey methods are well established in the evaluation of information technology, and the veteran response rates were relatively high compared with Web-based surveys conducted on other government Web sites. ${ }^{6}$ Nonetheless, a response rate of $47 \%$ is typically lower than standard in community-based surveys through mail or phone solicitation. It is unclear how this would alter the interpretation of the results, although one may speculate that those with more developed computer skills would agree to complete an online survey. Similarly, in this sample, $70 \%$ were in-person authenticated, indicating a more computer-literate sample. Prior analysis indicates that the demographic characteristics of survey respondents match those of the total population of veterans registered on My HealtheVet, ${ }^{6}$ mitigating some of the concern about representativeness of the sample surveyed. 
Table 4. Transfer of Medication Information to Veterans Affairs and Non-Veterans Affairs Providers: Wave Two $(N=18,471)$

\section{$N(\%)$}

DO YOU USE MY HEALTHEVET

PHARMACY SELF-ENTERED MEDICATIONS + SUPPLEMENTS ${ }^{a}$
IF YES $(N=5,490)$ : IN THE LAST 12 MONTHS, DID YOU SHARE YOUR MY HEALTHEVET, "MY COMPLETE MEDICATIONS LIST" WITH ANY OF YOUR VA HEALTHCARE PROVIDERS? NON-VA HEALTHCARE PROVIDERS?

\begin{tabular}{l|c|c|c}
\hline Yes & $5,490(30)$ & $3,295(60)$ & $1,780(32)$ \\
\hline No & $9,552(52)$ & $1,628(30)$ & $3,435(63)$ \\
\hline Not sure & $3,429(18)$ & $567(10)$ & $275(5)$ \\
\hline
\end{tabular}

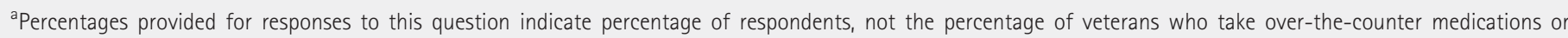
medications prescribed by non-VA providers.

In addition to sample bias, survey questions and possible responses were not mutually exclusive. For example, veterans were asked whether they printed out information and then separately asked if they sent information to another person. It is likely that many may print their information to share with someone else, but there were not follow-up questions asking veterans what they did with their printed information. If that is the case, there was more than one potentially accurate response to the survey questions.

Many My HealtheVet users are transferring important medical information from their PHRs, yet they remain a minority of total users. It is unclear if those who do not transfer their PHR information have concerns about doing so, such as privacy or stigma, or if it reflects lack of awareness of this PHR function. Given the increasing fragmentation of care, many involved in the development of PHRs hope patient access to their health information will improve provider and patient communication. The modest rates of actual sharing with providers combined with a considerable portion of this sample responding that they do not know if they are transferring information indicates that health literacy and training may be issues. ${ }^{12}$ Wakefield et al. $^{13}$ present the considerations when deploying Web portal communication systems, with a priori allocation of resources for training as essential to proper implementation. This study confirms that more upfront user training, particularly for those with low computer literacy, may be needed before patients realize the full potential of PHRs.

\section{Acknowledgments}

Dr. Turvey is a Research Health Science Specialist in the Comprehensive Access \& Delivery Research and Evaluation (CADRE) Center, Iowa City VA Health Care System. The work reported here was supported by the Department of Veteran Affairs, Health Services Research and Development Service through the eHealth QUERI, the CADRE Center, and the Veterans Rural Health Resource CenterCentral Region, VA Office of Rural Health. The views expressed in this article are those of the authors and do not necessarily represent the views of the Department of Veterans Affairs.

\section{Disclosure Statement}

No competing financial interests exist.

\section{REFERENCES}

1. Ross S, Moore L, Earnest M, Wittevrongel L, Lin C. Providing a web-based online medical record with electronic communication capabilities to patients with congestive heart failure: Randomized trial. J Med Internet Res 2004;6:e12.

2. Schnipper J, Hamann C, Ndumele C, Liang C, Carty M, Karson A, et al. Effect of an electronic medication reconciliation application and process redesign on potential adverse drug events: A cluster-randomized trial. Arch Intern Med 2009; 169:771-780.

3. Kaelber D, Shah S, Vincent A, Pan E, Hook J, Johnston D, et al. The value of personal health records. Boston: Center for Information Technology Leadership, 2008.

4. Ralston J, Carrell D, Reid R, Anderson M, Moran M, Hereford J. Patient web services integrated with a shared medical record: Patient use and satisfaction. J Am Med Inform Assoc 2007; 14:798-806.

5. Zhou Y, Kanter M, Wang J, Garrido T. Improve quality at Kaiser Permanente through e-mail between physicians and patients. Health Aff 2010;29:13701375.

6. Nazi K. Veterans' voices: Use of the American Customer Satisfaction Index (ASCI) Survey to identify My HealtheVet personal health record users' characteristics, needs, and preferences. J Am Med Inform Assoc 2010;17:203211.

7. Carey K, Montez-Rath ME, Rosen AK, Christiansen CL, Loveland S, Ettner SL. Use of VA and Medicare services by dually eligible veterans with psychiatric problems. Health Serv Res 2008;43:1164-1183.

8. Wolinsky FD, Miller TR, An H, Brezinski PR, Vaughn TE, Rosenthal GE. Dual use of Medicare and the Veterans Health Administration: Are there adverse health outcomes? BMC Health Serv Res 2006;6:131.

9. Hargreaves J. Will electronic personal health records benefit providers and patients in rural America? Telemed J E Health 2010;16:1-10.

10. Wood FB, Siegel ER, Feldman S, Love CB, Rodrigues D, Malamud M, et al. Web evaluation at the US National Institutes of Health: Use of the American 


\section{TURVEY ET AL.}

Customer Satisfaction Index online customer survey. J Med Internet Res 2008; 10:e4.

11. Valdiserri RO, Nazi K, McInnes DK, Ross D, Kinsinger L. Need to improve routine HIV testing of U.S. veterans in care: Results of an Internet survey. J Community Health 2010;35:215-219.

12. Sarkar U, Karter AJ, Liu JY, Adler NE, Nguyen R, Lopez A, et al. The literacy divide: Health literacy and the use of an internet-based patient portal in an integrated health system-results from the Diabetes Study of northern California (DISTANCE). J Health Commun 2010;15(Suppl 2):183196.

13. Wakefield DS, Mehr D, Keplinger L, Canfield S, Gopidi R, Wakefield BJ, et al. Issues and questions to consider in implementing secure electronic patientprovider web portal communications systems. Int J Med Inform 2010;79:469477.
Address correspondence to:

Carolyn L. Turvey, Ph.D. Center for Comprehensive Access \& Delivery Research and Evaluation (CADRE) Iowa City VA Health Care System 601 Highway 6 West 152, Suite 40 Iowa City, IA 42286

E-mail: carolyn-turvey@va.gov

Received: June 3, 2011

Revised: July 13, 2011 Accepted: July 14, 2011 
This article has been cited by:

1. Rajani S. Sadasivam, Rebecca L. Kinney, Stephenie C. Lemon, Stephanie L. Shimada, Jeroan J. Allison, Thomas K. Houston. 2013. Internet health information seeking is a team sport: Analysis of the Pew Internet Survey. International Journal of Medical Informatics 82:3, 193-200. [CrossRef] 